\title{
THE NEW BYE-LAWS
}

Members will have noted in my report to the Quarterly Meeting held on 7 February 1979 that the Privy Council has approved alterations to our Byelaws. The most important of these refers to the creation of the Collegiate Trainees Committee. The background to this is described in Dr John Hamilton's article which follows. Collegiate Trainees include Inceptors and also Senior Trainees who have held the Membership of the College for not more than three years. Appropriate nomination papers and ballot papers have been prepared and the new Committee will have been elected by the time of the Annual Meeting in July.

The other changes to the Bye-laws are relatively minor but nevertheless important. The word 'Regional' has been dropped from the official title of the Divisions, and the Child Psychiatry Section becomes the Child and Adolescent Psychiatry Section. There is now no upper age limit for entry to Inceptorship. Examiners may serve for five years (instead of the previous maximum of three years); members of Council who are examiners may now receive fees for participating in the examinations, though not for other purposes.

The process of producing new Bye-laws and having them approved by the Privy Council is lengthy and costly and requires a great deal of work and attention to detail. The College is grateful to all those who have helped. It is not likely that we will be going back to the Privy Council in the near future, but the Bye-laws will continue to be reviewed and suggestions for future changes are welcomed.

Gr.rald Timbury, Registrar.

\section{THE COLLEGIATE TRAINEES COMMITTEE}

The Privy Council's acceptance of the College's request to change the Bye-laws to allow the constitution of a Collegiate Trainees Committee marks the end of a period of representation of trainees on College committees which began at the College's foundation with a mere two Affiliates on the College Council.

At that time, in 1971, there was a feeling among trainees that under the College's constitution, as insisted on by the Privy Council, this representation was inadequate. The number of Affiliates (ex-members of the RMPA who were not qualified to become Foundation Members of the College) was destined to diminish; Inceptors had no rights of representation whatsoever; the class of Inceptor itself was to end after ten years; and new Members were less likely to be successful in elections than their more senior colleagues. Trainees believed that they had something to offer and that they were after all the 'consumers' of the training activities of the College. Existing RMPA members felt they had been disenfranchised by the new structure.

Following pressure by the Association of Psychiatrists in Training, the College agreed to set up a Trainees Working Party in 1973 as a sub-committee of the Education Committee, and whilst this has functioned well in the discussion of matters affecting trainees it has been constrained in promoting its views by its low place in the College hierarchy of committees. Furthermore, it is not a democratically elected body, representatives often being nominated ad hoc by a Division Secretary.

Similarly, the trainees who have been co-opted on to Standing Committees, Specialist Section Executives and Divisions' Executive Committees have been selected rather than elected, and some trainees feel they are there by 'grace' rather than right.

The new Bye-laws provide for the establishment of the Collegiate Trainees Committee as a Special Committee of Council, with direct responsibility to Council and it will therefore function as a Junior Council'. It will be composed of one Senior Trainee and two Inceptors elected by and from these categories in each Division; the Scottish and Irish Divisions will have two Senior Trainees and four Inceptors each. A Senior Trainee is defined as one who has passed his Membership examination and was registered as a Member not more than three years ago.

Senior Trainees and Inceptors will be the junior representatives for that Division and two of their number will sit on their Division's Executive Committee: which two of the three (or six) these are will be agreed by themselves or failing that be decided by the Division Executive. Elections of junior representatives will take place every two years; should a junior representative become a Member of the College or pass the three year period defining a Senior Trainee he will be permitted to continue as represen- 